\title{
1988 MRS \\ Spring Meeting in Reno Features Interdisciplinary Research "Revue"
}

\section{Spotlight Falls on Technical Topics, Short Courses, Equipment Exhibit, MicroScapes Photomicroscopy Exhibit}

Attendees at the 1988 MRS Spring Meeting in Reno may not have hit a jackpot in the casino, but they did leave with a wealth of information from the research "revue" spotlighting over 1,700 attendees, 983 papers, 71 companies exhibiting analytical and processing equipment, 23 short courses, 16 topical symposia (some held in theater settings), and the Microscapes photomicroscopy exhibition. Chaired by Dave Clark (University of Florida), Clif Draper (AT\&T Engineering Research Center), and C.T. Liu (Oak Ridge National Laboratory), the meeting events in Reno, Nevada, spanned April 410, 1988.

"The meeting offered a thorough examination of mainstream topics, such as heteroepitaxy, superconductivity, chemical routes to ceramics, adhesion, and optoelectronics," said meeting chair C.T. Liu. "It also presented a selection of intriguing new topics, including microwave processing, environmental stability, and materials for controlled-release environments," added Dave Clark. Commenting on the creativity inherent in art and science as a common bond between the two, Clif Draper saw "the fruition of interdisciplinary dialogue in a first-time symposium for MRS on materials issues in art and archeology, and in the MicroScapes photomicroscopy exhibition."

In addition to oral and poster presentations, joint sessions, and panel discussions, the luncheon tutorials scheduled for Symposium X, Frontiers of Materials Research, hosted by Rustum Roy of the
Pennsylvania State University, provided state-of-the-art presentations by experts on topics relevant to the meeting. [The presentations will be published in the Joumal of Materials Education.] Raymond D. Tuminaro of AT\&T Bell Laboratories provided yet another state-of-the-art focus in his plenary address on "Materials Aspects of the SL Undersea Optical Cable Design," published elsewhere in this issue.

These pages only highlight the many aspects of the 1988 MRS Spring Meeting. Readers interested in detailed technical content of the symposia are encouraged to order MRS Symposium Proceedings or Extended Abstracts (see pages 49 and 52) and to contact the symposium organizers and authors directly.
Graduate Student Awards were presented to: (seated, left to right) Timothy $P$. Weihs, Sangeeta D. Ramamurthi, Ping Mei, Mansoor Ali Khan; (standing, left to right) Jaejun Yu, Bruce K. Zoitos, Juergen Roedel, Robert W. Schwartz, and Finley R. Shapiro.

Spring Meeting attendees autographed the poster marking the debut of Volume 100 of the MRS Symposium Proceedings Series. Volume 100, Fundamentals of Beam-Solid Interactions and Transient Thermal Processing, contains the papers from the 1987 MRS Fall Meeting symposium on this topic. The 1987 symposium was the 10th in a series of MRS symposia that began with the 1978 symposium on Laser Solid Interactions and Laser Processing. The editors of Volume 100 are Michael J. Aziz (Haroard University), Lynn E. Rehn (Argonne National Laboratory), and Bernd Stritzker ( $\mathrm{Nu}$ clear Research Center, Jülich).

Glass "Eggshells," one of 50 photographs from the Microscapes exhibition, is a scanning electron micrograph, about 3,300X by Robert Woods. Photographed by ATET scientists and photographers; the exhibition is on a three-year tour of the United States under the auspices of the Association of Science-Technology Centers.

Poster session papers, which have doubled since the 1987 MRS Spring Meeting, offer an excellent opportunity for individual discussions and in-depth conversations.

Short Course Program Roars into 1988-Jim Mayer (first row, right), one of the instructors for the MRS course on Surface and Thin Film Analysis, insisted that his co-instructor, Leonard Feldman (first row, left), finish the course 15 minutes early to allow the attendees and Vivienne Harwood Mattox, the Short Course Manager (next to Feldman), to be photogmaphed with the lion who lives in the lower level of Bally's Reno.

The success of the 1988 MRS Spring Meeting is directly related to the enthusiasm and commitment of many people. Outstanding in this group we salute:

Dave Clark, Clif Draper, C.T. Liu, and their cadre of symposium organizers for planning an enriching program with unusual depth and breadth;

Marilyn Hauck and Merilyn Bowman of The Complete Conference for exemplary on-site management of a diverse and challenging meeting;

Vivienne Harwood Mattox for development and management of an outstanding short course program;

Bob Finnegan and Ed Greeley of the American Institute of Physics for managing the growing equipment exhibit; and

Beverly Citrynell of the American Institute of Physics for organizing the Job Placement Center.

\section{KUDOS}




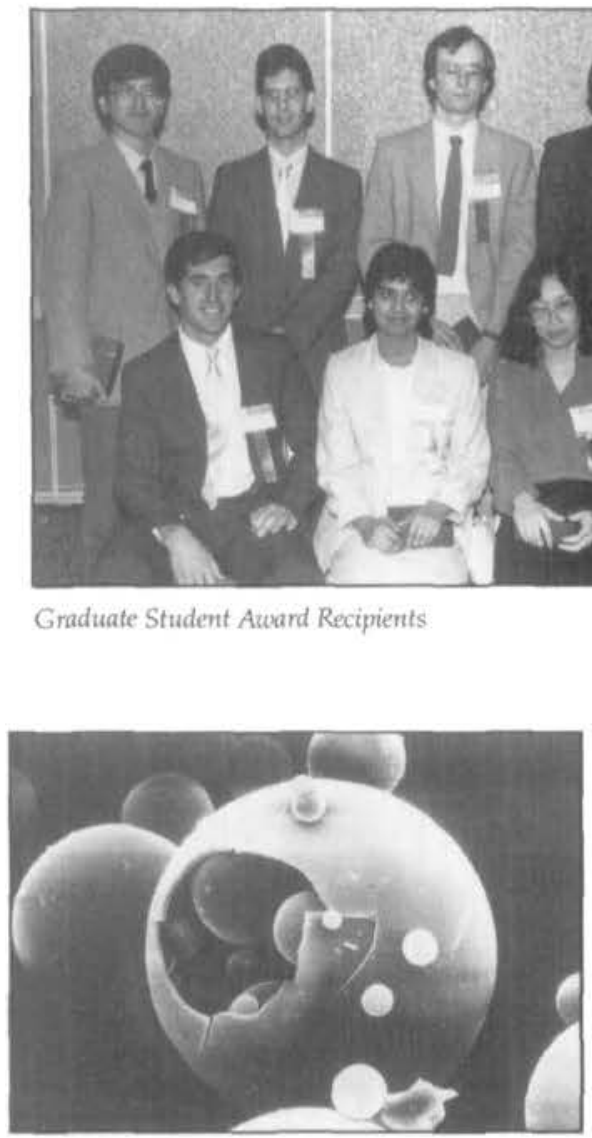

MicroScapes
Volume 100 MRS Symposium Proceedings
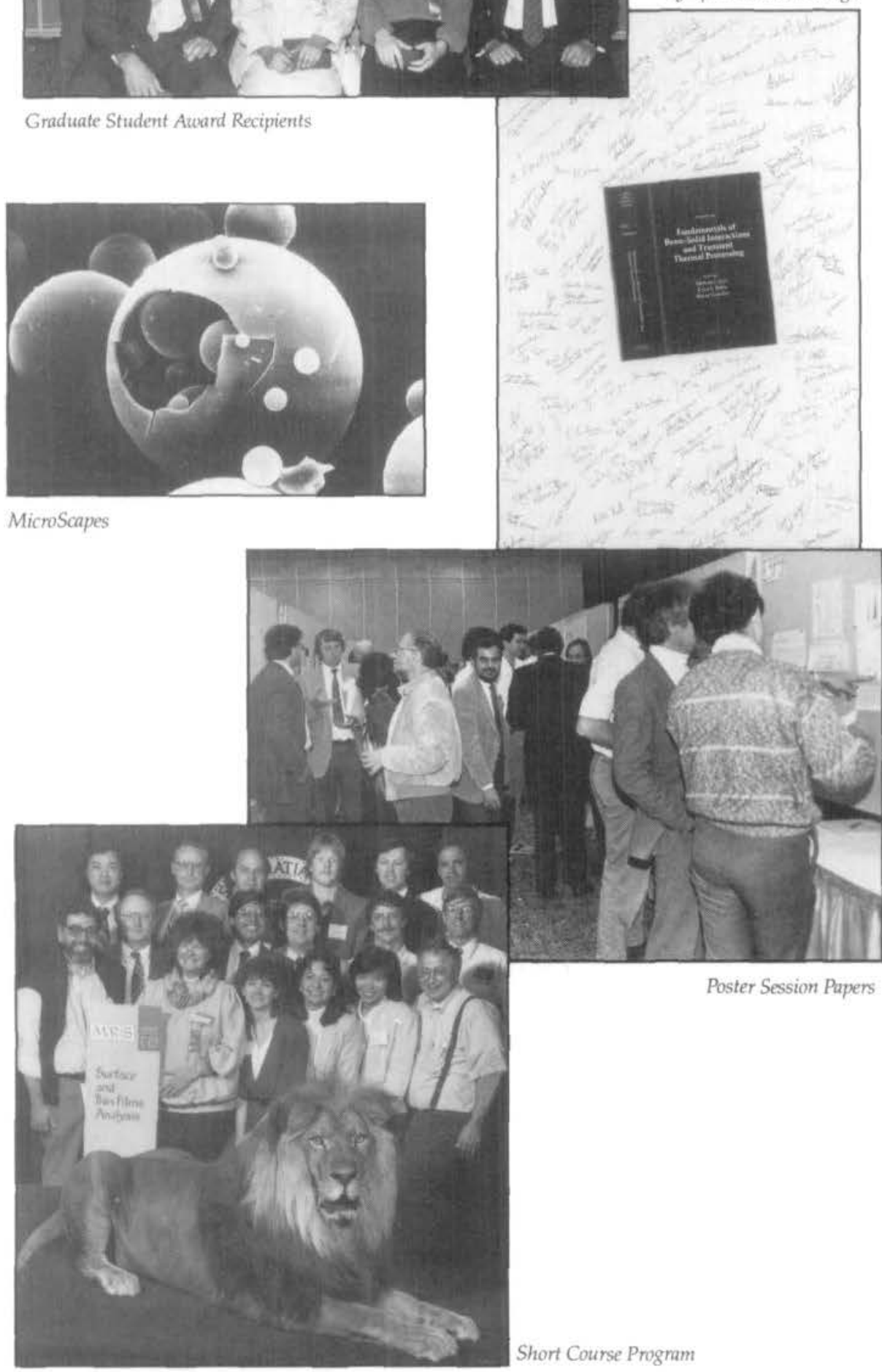

\section{Short Course Program}

In Reno, the MRS Short Course Program provided a diverse educational opportunity for those interested in broadening their knowledge in materials characterization, growth of compound semiconductors, thin film formation and adhesion, high temperature superconductivity, ceramic and metal matrix composites, sol-gel processing, microelectronic packaging, IC failure analysis, plasma etching, amorphous semiconductor materials and devices, ion implantation, and optoelectronic materials.

Attendees' comments on the course evaluation forms attest to the success of this program:

"The course was comprehensive and well presented...exactly what I needed at this point."

"Lecturers had a refreshing enthusiasm, were very open to questions and willing to address technical problems relating to our own facilities."

"I found this course extremely beneficial. It cleared up confusions I've had over many subjects over many years! Excellent lectuiner."

"Instructor did a superb job of communicating and teaching without overpowering...he knows the key points to emphasize with just enough detail to be clear and convincing."

"Many aspects of the course apply directly to my area of work."

"Great handouts and a lot of valuable side tips."

MRS acknowledges the following organizations for their assistance in the promotion of the Short Course Program: Shawmco, R.D. Mathis, Perkin-Elmer, JEOL, Spire Corporation, American Instruments, Nissei Sangyo America, Ltd. CVC, Quantachrome, SAMPE, Solid State Technology, Optical Engineering, Instruments SA, Princeton GammaTech, NCSEM, Gatan, Carl Zeiss, Inc., Huntingdon Laboratories, Process Products Corp., Microscience, Nanosil.

Vivienne Harwood Mattox MRS Short Course Manager 


\author{
Heteroepitaxy on Silicon: \\ Fundamentals, Structures, and \\ Devices-A \\ MRS Symposium Proceedings, \\ Vol. 116
}

Organizers: H.K. Choi (MIT Lincoln Laboratory), R. Hull (AT\&T Bell Laboratories), H. Ishiwara (Tokyo Institute of Technology), R.J. Nemanich (North Carolina State University)

Support: EMCORE Corporation, Kopin Corporation, Oki Electric Corporation, Perkin-Elmer (Physical Electronics Division), Shimadzu Corporation, VG Semicon

This symposium consistently drew a large, knowledgeable and enthusiastic audience throughout its three and a half days with approximately 80 invited and contributed oral and poster presentations.

As in previous years, the greatest interest centered on growth of GaAs and other III-V compound semiconductors on $\mathrm{Si}$. Two lively sessions on this materials combination were highlighted by excellent talks by M. Akiyama and D.K. Biegelsen on fundamental materials aspects of this system, and by A. Yamomoto on the OMVPE growth of GaAs, GaP and InP on Si surfaces. One major new direction in $\mathrm{GaAs} / \mathrm{Si}$ was epitaxial growth onto patterned substrates, as described by J.W. Adkisson, R.J. Matyi, and H.P. Lee. Progress in the growth of optical devices on $\mathrm{Si}$ substrates was reviewed by R.D. Dupuis and G.W. Turner for GaAs-AlGaAs/ $\mathrm{Si}$ and $\mathrm{M}$. Razhegi who presented exciting, last-minute results on laser operation in InP-InGaAsP/Si. Wider prospects for optoelectronic integration of III-V compounds on Si substrates were subject to a lively discussion in an evening panel session chaired by J.C.C. Fan.

A strong feature of this symposium was the emergence of interest in new heteroepitaxial combinations on $\mathrm{Si}$ substrates, highlighted by invited talks by $\mathrm{H}$. Matsunami and R.F. Davis on the SiC/Si system. Other more novel materials combinations discussed included $\mathrm{ZrO}_{2} /$ $\mathrm{Si}, \mathrm{Al}_{2} \mathrm{O}_{3} / \mathrm{Si}$ and $\mathrm{SrTiO}_{3} / \mathrm{Si}$.

New directions in the growth and characterization of epitaxial fluorides and silicides on Si were described by J.M. Phillips and by L.J. Schowalter, who also gave an excellent general overview of heteroepitaxial growth by MBE. Exciting new results were presented on growth of GeSi alloys, highlighted by a review of technological prospects by J.C. Bean, and significant progress in the understanding of strained layer epitaxy by B.W. Dodson. P. Pirouz summarized and extended our under- standing of defect structures in latticemismatched films.

This was an exciting symposium which highlighted work in new materials systems and revealed new approaches to old problems in more established heteroepitaxial combinations.

\section{Materials for Controlled-Release Environments-B}

Organizers: K. Knutson (University of Utah), R. Langer (Massachusetts Institute of Technology), R.A. Siegel (University of California)

The symposium focused on materials properties of polymers, ceramics, liquid crystals, and skin as they relate to the controlled release of pharmaceutical and agrichemical agents. Biocompatibility properties of such materials were also discussed. Major topics included: environmentally sensitive hydrogels, whose swelling and permeability to solutes is altered by the solvent and/or ionic environment; bioerodible polymers that release incorporated agents as they erode; and permeability of the skin to drugs, which may be modified by the coadministration of "penetration enhancers."

A novel entry to the controlled release field. described for the first time in this meeting, was the use of porous aluminum oxide ceramics as solute permeation barriers. Also of major interest was the description of a bioerodible polyanhydride system that may be implanted into the brain. The system releases an antitumor drug over long periods of time and has successfully extended the lives of patients suffering from acute brain tumors.

\section{Process Diagnostics-C MRS Symposium Proceedings, \\ Vol. 117}

Organizers: K. Hays (Sandia National Laboratories), G. Campbell (Plasma Materials Technologies), A. Eckbreth (United Technologies Research Center)

Support: Air Force Office of Scientific Research, Army Research Office, DARPA, Leybold Infacon, Leybold Technologies

This symposium was the first of its kind devoted to bringing together the relatively small number of researchers working in the emerging area of diagnostics for materials processing and investigators working in the well-established fields of combustion and magnetic confinement fusion diagnostics. Speakers in the combustion and fusion areas gave overviews of the principal diagnostic techniques (CARS [coherent anti-Stokes Raman spectroscopy], laser-induced fluorescence, multiphoton excitation spectros- copy, interferometry, fast plasma probe techniques, optical imaging diagnostics, frequency modulation spectroscopy, spontaneous Raman spectroscopy, etc.) and their relevance so that the symposium proceedings could serve as a textbook for a graduate course on process research in chemical engineering or materials science.

The atmosphere of this symposium was that of a small Gordon conference, with the setting very conducive to sharing of research plans and establishing joint experiments. Several new diagnostic techniques and instrumentation developments were previewed at the symposium. Of particular note were talks by Rick Gottscho of AT\&T Bell Laboratories on the use of Optogalvanic Spectroscopy as a diagnostic in plasma etching environments, by Norman Laurendeau of Purdue University on the use of Asynchronous Optical Sampling in combustion environments, and by Dave Pearson of Plasma Materials Technologies on the development of a microwave interferometer to measure electron density in process plasmas.

\section{Diamond and Diamond-Like \\ Materials Synthesis-D}

MRS Extended Abstracts, Vol. EA-15

Organizers: G.H. Johnson (E.I. duPont de Nemours \& Company), A.R. Badzian (Pennsylvania State University), M.W. Geis (Massachusetts Institute of Technology)

Support: Pennsylvania State University, Diamond Consortium; Crystallume; Diamond Materials Institute, Inc.; E.I. du Pont de Nemours; General Electric; North American Phillips Corporation

This symposium, a continuation of Symposium N, Plasma-Assisted Deposition of New Materials, held during the 1987 MRS Fall Meeting in Boston, was devoted to low pressure synthesis, structure, and properties of diamond films.

Invited speakers covered the following current topics:

Boris V. Spitsyn (Institute of Physical Chemistry, Moscow) who 20 years ago began studying chemical transport reaction between graphite and substrate, in a hydrogen atmosphere, described properties of diamond films obtained by this method. A microwave plasma-enhanced chemical vapor deposition process was the topic of the talk by Y. Sato (National Institute for Research in Inorganic Materials, Japan).

The issue of intensifying the plasma to achieve a high growth rate of diamond was presented by S. Matsumoto (NIRIM) and N. Koshino. Dr. Koshino showed a 
photograph of a one-millimeter-thick polycrystalline diamond film obtained by direct current plasma jet.

Growth of diamond films on refractory metals was presented by B. Lux (Austria). Amorphous carbon materials which possess some properties close to that of diamond were discussed by P. Koidl (Federal Republic of Germany) and other authors.

One session was devoted to diamond film characterization with electron microscopy (lattice imaging of the interface of silicon and diamond and meteoritic residues), Raman Spectroscopy, cathodoluminescence, ellipsometry, wear and adhesion behavior.

The prospective application of diamond films to electronic devices was covered by M. Geis (MIT). The transformation of graphite to diamond in the solid state by laser zapping, and the impact of this discovery was discussed by Rustum Roy (Penn State). In conclusion, the symposium was able to cover the most important topics of diamond synthesis and to show that great progress has been achieved since the last meeting.

\section{Amorphous Silicon Technology-E MRS Symposium Proceedings, Vol. 118}

Organizers: Y. Hamakawa (Osaka University), P.G. LeComber (University of Dundee), A. Madan (Glasstech Solar, Inc.), P.C. Taylor (University of Utah), M.J. Thompson (Xerox PARC)

Support: ARCO Solar, Inc.; Philips Research Laboratories; Sanyo Electric Co., Ltd.; Pilkington plc; Siemens Aktiengesellschaft; Amoco Corporation; IBM Corporation; Hitachi, Ltd.; Fuji Electric Corporation of America; Solar Energy Research Institute; Xerox; 3M Co.; Solarex Corp.; Komatsu Ltd.; Glasstech Solar, Inc.

This symposium presented a balanced blend of basic science and device technology. Perhaps its most notable feature was the large number of novel applications of a-Si: $\mathrm{H}$ beyond the more traditional solar cell and thin film transistor (TFT) Display devices. A novel a-Si:H position sensor product was described for transmitting graphical information from a telephone terminal. Papers on high speed light modulators, neural networks, UV detectors, diode addressed liquid crystals, imaging devices, and electrophotography attracted considerable attention.

The number of applications of TFT devices has also increased dramatically. As described in the symposium, the integration of conventional (low voltage) TFTs, of high-voltage TFTs, and of short channel vertical transistors which offer increased speed and resolution are likely to be responsible for an even greater growth of applications in the immediate future.

Solar cell technology employing a-Si:H and related alloys is really beginning to mature. This maturity was underscored during a panel discussion when representatives from several prominent companies showed optimistic projections of worldwide a-Si: $\mathrm{H}$ solar cell production in five years. Current module (approximately $1 \mathrm{ft}^{2}$ ) efficiencies are around $6-8 \%$, and single-cell efficiencies approaching $13 \%$ were also reported.

The basic research reported at the symposium covered a wide range of topics including film morphology and growth, stability and hydrogen diffusion, defects and metastabilities, multilayers and alloys.

Perhaps the most exciting new development was the report by the group from Osaka University (Prof. Yoshihiro Hamakawa, Dr. Hiroaki Okamoto, and colleagues) who, from thermally modulated absorption measurements, appear to have obtained the first strong evidence for "quantum confinement" in their amorphous multilayer structures. If these results are confirmed they may have farreaching consequences both for our understanding of the electronic states in amorphous semiconductors and for the production of devices similar to those based on quantum well and superlattice structures in III-V crystalline semiconductors.

\section{Adhesion in Solids-F MRS Symposium Proceedings,} Vol. 119

Organizers: J.E.E. Baglin (IBM Almaden Research Center), D.M. Mattox (Sandia National Laboratories), C. Batich (University of Florida), R.J. Gottschall (USDOE)

"Adhesion in Solids" was a forum for a diverse agenda on adhesion and interfacial phenomena, covering fracture mechanics of interfaces, tribology, adherence of natural layers, surface treatments, interfacial reactions, and means of modifying interfaces to improve their properties. Presentations ranged from the theoretical to the technological with a great deal of interaction between the two extremes.

Of particular interest were several papers on the fracture mechanics of interfaces between dissimilar materials. A major problem in this area is the lack of knowledge of the properties of the "interphase" material that exists in the interfacial region.

Several papers considered how the properties of deposited coatings could affect the apparent adhesion of the films to substrates. Papers on the modeling of adhesion measurements and frictional studies using the new technique of atomic force microscopy reviewed the latest work in those areas. Papers on the surface preparation of and adhesion to polymers demonstrated the wide range of thinking about the important factors in this particular system. Also presented were a number of analytical techniques for investigating surfaces and interfaces.

\section{High Temperature/High Performance Composites-G}

MRS Symposium Proceedings,

Vol. 120

Onganizers: F.D. Lemkey (United Technologies Research), S.G. Fishman (Office of Naval Research), A.G. Evans (University of California), J.R. Strife (United Technologies Research)

\section{Support: DARPA}

The development of future generations of aerospace structures, propulsion devices, and energy conversion systems will rely on new high performance/high temperature composite materials. Forty-one invited and contributed papers were presented in five sessions concerning the synthesis, structure-property relationships, interfacial effects, and mechanics of metal, intermetallic, glass and ceramic matrix composites. Highlights of each of the sessions will be given.

Many of the intermetallic compounds possess properties which make them excellent candidates for high temperature application, but their low temperature ductility limits their use. The composite approach has been utilized to increase damage tolerance. A variety of consolidation techniques ranging from reactive hot pressing of powders, in situ castings, codeformation, and chemical vapor deposition to the proprietary $X D^{\mathrm{TM}}$ and Lanxide $^{\mathrm{TM}}$ processes were discussed with special attention to the composition and/ or thickness of the interaction zone between reinforcing and matrix phases.

A number of investigations had the objective of developing quantitative expressions for the relationship between the toughness of brittle or ductile matrix composites and microstructures. Such expressions would provide microstructural goals for the production of tough composites. Papers were presented on a number of engineering composites systems and on model experiments, analytical modeling, and numeriçal simulations.

Some of the most interesting contributions concerned the microstructural study of the interfacial zone of a fiber reinforced composite. Prof. Ruhle's work at University of California, Santa Barbara shed new 
light on the much heralded UTRC LAS/ $\mathrm{SiC}$ glass-ceramic high temperature composite. In the as hot pressed state, the interfaces of amorphous $C$ and carbides of $\mathrm{Nb}$ were confirmed with the circumferential thermal debonds evident in the carbon layer. After heat treatment in air at $800^{\circ} \mathrm{C}$, the carbon was found to be replaced by amorphous $\mathrm{SiO}_{2}$ and the carbides of $\mathrm{Nb}$ replaced by oxides.

\section{Better Ceramics Through Chemistry III-H \\ MRS Symposium Proceedings,}

Vol. 121

Organizers: C.J. Brinker (Sandia National Laboratories), D.E. Clark (University of Florida), D.R. Ulrich (Air Force Office of Scientific Research)

Support: Air Force Office of Scientific Research

This third MRS symposium on Better Ceramics Through Chemistry was intended to unite chemists and physicists with ceramists and material scientists in order to synthesize new and better ceramic materials by solution routes involving molecular precursors. This year's symposium was distinguished from the previous two by several factors: (1) the participation of a greater number of chemists and chemical engineers; (2) more extensive use of in situ methods of characterization; (3) emphasis on sol-gel derived films; and (4) the inclusion of a session on "Better Superconductors Through Chemistry." Over 300 conferees were in attendance for several of the sessions including sol-gel chemistry and superconductors.

Highlights included the session on solgel chemistry of silicates where lively discussions focused on evidence for thermodynamic versus kinetic control in silicate polymerization pathways. Silicate speciation and hydrolysis and condensation kinetics were elucidated in several studies using ${ }^{20} \mathrm{Si} \mathrm{NMR}$, the most sophisticated approach employing 2D INADEQUATE ${ }^{29} \mathrm{Si} N \mathrm{NMR}$. In addition to NMR, other in situ methods discussed in the characterization and poster sessions included small angle scattering, photophysical probes, surface acoustic wave (SAW) techniques, cryogenic transmission electron microscopy (TEM), ${ }^{1} \mathrm{H}$ spin relaxation, and positronium decay.

In the session on films, ellipsometric imaging was employed to study film formation in situ. An approach to thick $(>1 \mu \mathrm{m})$ films based on organic modification was presented, and an approach to novel zeolite/gel composites for sensor surfaces was described.

\section{Interfacial Structure, Properties and Design-I \\ MRS Symposium Proceedings,}

Vol. 122

Organizers: M.H. Yoo (Oak Ridge National Laboratory), W.A.T. Clark (Ohio State University), C.L. Briant (General Electric Corporate Research and Development)

Support: Office of Basic Energy Sciences, Department of Energy; Division of Materials Research, National Science Foundation; General Electric Company; Rockwell International Corporation; JEOL USA Inc.

This truly international symposium brought together experts from five continents to discuss the present status of our understanding of the interrelationship of the structure and properties of interfaces and the prospects for utilizing this insight in engineering practice. It is an invidious task to select highlights from what was a consistently well-attended and highquality program. Even so all participants will remember the impact of the observations reported in the papers by Chisholm, Kroeger et al. and Ishida et al., each of which related directly to the maniner in which grain boundary structure and chemistry depended on processing and affected critical currents in high $T_{c}$ ceramic superconductors.

An equally satisfying example of the relevance of the theoretical and experimental techniques developed in fundamental studies of interfaces appeared in the sessions devoted to elasticity and localized deformation and cohesive strength and intergranular structure. Theory presented by Bonnet, experiments discussed by Thibault-Desseaux and Elkajbaji, Clark et al. and Qian and Chou, and modeling reported by Chen et al. exemplified the emerging understanding of the atomistic processes which occur during yielding of metals, alloys, compounds, and semiconductors. These insights relate directly to the spectacular and important ductilizing effect of boron additions to $\mathrm{Ni}_{3} \mathrm{Al}$ described in this symposium by Choudhury et al. and Liu.

An exciting and significant, albeit frustrating to some, development was that just as the crystallography of interfacial defects had been put on a rigorous intellectual basis by Pond, the question of the broad physical applicability of the dislocation model of interfaces was called into question by the modeling discussed by Sutton for mixed tilt and twist boundaries. A similar argument has been propounded, on the basis of the analysis of high angle twist boundaries by Wolf et al.
It emerged that a deep understanding of the behavior of interfaces came from experiments in which great care was given to preparing and characterizing the specimens to be investigated. One avenue is the production of oriented bicrystals and biphase samples either by variants of classical single-crystal pulling techniques or by refining the thin film welding technique established by Balluffi. The UHV welding process described by Fischmeister and Mader was an impressive step in this direction as was the elegant lithographic technique for controlling interfacial voids by Rodel and Glaeser.

For polycrystals the control and measurement of grain boundary orientation distribution offers a way to engineer and understand the properties of polycrystals in the manner well known for transformer laminations but perhaps, according to Watanabe extendable to other contexts.

This symposium can be adjudged a major success with its formula of bringing together established and younger scientists to participate in a broadly based technical program which demonstrably pointed the way forward in the dynamic field of interface science.

\section{Science and Technology of Refractory Metals-J}

Organizers: R.H. Cooper Jr. (Oak Ridge National Laboratory), R. Gibala (University of Michigan), C.M. Packer (Lockheed Palo Alto Research Center), J. Wadsworth (Lockheed Palo Alto Research Center)

This symposium reviewed the technology associated with refractory metal alloy systems based on niobium, tantalum, tungsten, molybdenum, and vanadium. Attention was directed to the processing, design, and performance of these materials for high temperature structural and electronic applications. Specifically discussed was important materials information relating to applications for fusion reactors, advanced propulsion systems, aerodynamic structures for hypersonic systems, and compact systems to provide prime power space-based assets.

Exciting new technical advances which may significantly benefit our lives were presented, and the symposium provided an excellent forum to review and discuss these advances.

\section{High Temperature Superconductivity-K} MRS Extended Abstracts, Vol. EA-14 Organizers: B. Batlogg (AT\&T Bell Laboratories), W.H. Butler (Oak Ridge National Laboratory), D. Capone (Argonne National Laboratories), P.[C.W.] Chu 
(University of Houston)

Support: Department of Energy, Division of Materials Science

Materials Research Society meetings have played an important role in the rapidly developing field of high temperature superconductivity. Reports at the Fall 1986 MRS Meeting that the "possible" high temperature superconductivity discovered by Bednorz and Mueller was in fact a reality sparked an avalanche of work and excitement that continues. The Spring 1987 MRS meeting had a hastily arranged symposium on high $T_{c}$ superconductivity and this was followed by a symposium at the Fall 1987 MRS Meeting.

Symposium K at the Spring 1988 MRS Meeting brought together about 500 researchers in high $T_{c}$ superconductivity. Fortunately, exciting new discoveries continue to be made. There were several talks on the very recently discovered $\mathrm{Bi}$ and $\mathrm{Tl}$ compounds. There appear to be two families of these compounds ( $\mathrm{a}$ Bi family and a Tl family), the family members distinguished by differing numbers of layers of copper-oxygen planes. Researchers from IBM reported that a member of the Tl family with three copper-oxygen layers has a transition temperature of $125 \mathrm{~K}$. One gets the impression that the field is becoming much broader since researchers now have several different materials to work with.

One also gets the impression that researchers are settling down to more careful and thorough research on these materials. There were numerous reports at the meeting of interesting and beautiful work on their properties. The atom positions, the magnetic properties, and the optical properties of the "older" superconductors $\mathrm{La}_{2 \times} \mathrm{Sr}_{x} \mathrm{CuO}_{4}$ and $\mathrm{YBa}_{2} \mathrm{Cu}_{3} \mathrm{O}_{7}$ ) are finally being determined unambiguously.

Much progress is being made in the processing of oxide superconductors. Researchers reported progress in applying chemical vapor deposition, molecular beam epitaxy, laser-assisted reactive deposition, aerosol flow reaction, and various chemical precipitation techniques to make the superconductors. Progress is also being made in increasing the critical currents of bulk materials. Researchers from AT\&T Bell Laboratories reported that they measured a critical current density of $4,000 \mathrm{~A} / \mathrm{cm}^{2}$ in a magnetic field of 1 tesla in a "melt-textured" sample of $\mathrm{YBa}_{2}-$ $\mathrm{Cu}_{3} \mathrm{O}_{7-\mathrm{x}}$.

Despite the continuing rapid progress in transition temperatures, critical fields, and other properties, prospects for major applications remain uncertain. Several analyses of possible applications of high temperature superconductors were pre- sented. Apparently for most large-scale applications of superconductivity such as power transmission, power storage, and high field magnets, "low $\mathrm{T}_{c}$ " metallic superconductors are still the most sensible materials. Advances in high $\mathrm{T}_{\mathrm{c}}$ superconductivity are coming so fast, however, that applications will certainly develop.

\section{Materials Issues in Art and \\ Archaeology-L \\ MRS Symposium Proceedings, \\ Vol. 123}

Organizers: E.V. Sayre (Smithsonian Institution), P. Vandiver (Smithsonian Institution), J. Druzik (Getty Conservation Institute), C. Stevenson (Archaeological and Historical Consultants, Inc.)

Support: Getty Conservation Institute

Co-Sponsor: Conservation Analytical Lab of the Smithsonian Institution

This symposium reviewed the methods and analytical techniques of materials science which have been central to advances in art history, archaeology, and conservation. Four general topics were addressed: (1) new technologies for nondestructive structural evaluation; (2) compositional studies to characterize materials used in works of art, define processes of deterioration and natural aging, and determine provenance or source raw materials; (3) measurements of structure-propertiesprocessing relationships which support reconstruction of metals, ceramics, pigment, glass and gem technologies; and (4) new technologies for conserving art and architecture. A joint session on the deterioration of natural, ancient and manmade glasses was sponsored joịntly with Symposium N.

Speakers in the session on structural and compositional analysis reviewed techniques for nondestructive macrostructural evaluation of architecture, sculpture and paintings, including use of cosmic rays, $x$-rays and neutron flux; gave examples of neutron autoradiography of paintings and CAT scan images of museum objects; evaluated new xeroradiography and stimulable phosphor technologies; introduced microscopic FTIR of painting media; and reviewed the application of elemental, molecular and isotopic compositional analyses to art conservation, identifying materials used in ancient technologies, sourcing raw materials and provenancing objects, dating and determining ancient animal and human diets. Other topics included problems evaluating surficial weathering products, determining ancient firing temperatures, neutron probe evaluation of brick wall composition and structure, evaluation of lead isotope data for the Aegean region, and analyzing museum collections by PIXE.

The session on ancient technology featured instances of modern engineered solutions to ancient materials problems, such as fiber-reinforced composite in Near Eastern neolithic pottery and the control of nucleation and growth, liquidliquid phase separation and local absorption and scattering centers in Chinese and Korean celadon glazes. Studies were presented of the Chinese Han dynasty terracotta army, Roman and Bronze Age ceramics, Maya blue, Indian diamond drilling of sapphires, and unusually durable glass beads. Ancient metals technology was explored in such topics as ancient Near Eastern bronze and iron metallurgy, solders for gold jewelry, British bronze cauldrons, Viking forging, and central European metal traditions.

Other authors described corrosion of the Statue of Liberty; presented sol-gel processes to conserve large stone sculpture; evaluated problems of preserving the Egyptian tomb of Nefertari; described salination of the structures at Karnak; evaluated criteria and materials for stained glass surface coatings; showed the effect of humidity on the fading of several organic colorants; and presented a laser treatment for modeling scorched textile surfaces. In addition, several authors evaluated the problems with and prospects for obsidian hydration dating and evaluated experimental corrosion studies of natural and manmade glasses.

Another similar symposium will take place at the Spring 1990 meeting. Future efforts will emphasize advances in our understanding of ancient technology, case studies of new analytical techniques for use in characterizing composition, structure and properties of ancient materials and the mechanisms of materials degradation as well as models for their stabilization. Topical suggestions for this meeting are welcomed by J. Druzik and P. Vandiver.

\section{Microwave Processing of \\ Materials-M}

MRS Symposium Proceedings,

Vol. 124

Organizers: W.H. Sutton (United Technologies Research Center), I.J. Chabinsky (I.J.C. Technologies, Inc.), M.H. Brooks (Genesis II)

Support: Materials Program, Energy Conversion \& Utilization Program, DOE; Microwave and Power Tube Division, Raytheon Co.

Endorsement: American Ceramic Society 
This symposium covered a broad range of materials: ceramics, minerals, chemicals, polymers, elastomers, wood products, and biomass and tissues. New to MRS meetings, the symposium drew an enthusiastic audience that participated in many lively discussions.

The advantages of microwave processing were discussed in many of the 44 papers and included: very rapid processing, achievement of improved or unique microstructures and properties, and significant savings of energy/costs. The following aspects of microwave processing were reviewed:

1. Fundamentals-microwave/materials interactions and mechanisms, internal heating behavior, sintering dynamics, modeling and predicting the thermal response of mixtures and composite materials.

2. Applications-drying of wood products, polymers, gels; sintering and joining of ceramics; producing ultra-pure $\mathrm{SiO}_{2}$ optical fibers; preparation of powders of superconducting materials; curing and cross-linking of polymers; enhancing the grindability of ores; bonding of automotive panels; new medical diagnostic techniques and treatment of tumors; reclamation of asphalt in large tonnages.

3. Equipment Design-development of special applications for high frequency or high power uses; plasma reactors for depositing thin films (such as diamond); high pressure chemical cells.

The symposium concluded with a panel discussion on new frontiers for $\mathrm{mi}$ crowave processing, on safety standards, and a review of activities in other nations (Australia, Britain, China, France, Germany, Japan, Sweden). About 50 people visited the U.S. Bureau of Mines Microwave Processing Laboratory in Reno. Plans are under way for another microwave processing symposium at the 1990 MRS Spring Meeting.

\section{Materials Stability and Environmental Degradation-iN MRS Symposium Proceedings,} Vol. 125

Organizers: A. Barkatt (Catholic University of America), L.R. Smith (National Bureau of Standards), E.D. Verink Jr. (University of Florida)

Support: DARPA; Air Force Office of Scientific Research

The symposium covered a broad range of subjects related to materials stability and corrosion phenomena, but several themes were repeatedly emphasized. In the search for high-performance materials in aggressive environments, stability and corrosion resistance, rather than cost and ease of fabrication, have become the primary considerations; combinations of materials, rather than single materials, are needed in many cases to satisfy such needs; understanding of corrosion and degradation mechanisms is a key element in the development of resistant materials; and studies of these mechanisms in different types of materials-metals, crystalline ceramics, and glasses-exhibit a surprisingly high potential for correlation and cross-fertilization.

Specifically, carbon-carbon composites have become the materials of choice for applications requiring high tensile strength and light weight at temperatures between 2000 and $3200^{\circ} \mathrm{F}$ despite their high cost $(\$ 411,000 / \mathrm{lb})$. Such applications include aircraft brake discs, missile nose tips, and rocket nozzle throats and exit cones. To provide oxidation resistance for such composites in space shuttle nose caps and wing leading edges, gas turbine engine components and missile propulsion components, such composites have to be coated with ceramic coatings. These and lower temperature composites will be extensively used in the National Air and Space Plane project (NASP). The development of such materials is based on study of the mechanisms of oxidation, volatilization, mutual chemical interaction, crack formation and attack by moisture.

The development of unifying thermodynamic and kinetic models of materials corrosion has already contributed to significant progress in several areas and is likely to have much greater impact in the future. The development and application of Pourbaix ( $\mathrm{pH}-\mathrm{Eh}$ ) diagrams for the stability of materials over a wide range of environmental conditions, initially used in metal corrosion, has been shown in this Symposium to provide a firm basis for the safe use of borosilicate glasses as immobilization media for high level nuclear waste over periods of $10^{3}-10^{5}$ years in geologic repository. At the same time, the use of stability diagrams in identifying stable phases which appear in natural minerals has made it possible to analyze the effects of acid rain and to lay the ground for combatting corrosion effects, e.g., in the restoration of the Statue of Liberty. Systematic studies of the reactivity of glass surfaces have given rise to identification of regions of glass composition which are sufficiently reactive to bond to human bone and soft tissue yet durable enough to re- sist dissolution in the body and are consequently suitable for use in implants.

An area where fundamental mechanistic studies have resulted in major improvements in safety and large cost savings is stress corrosion in ceramics, glasses, and metals. Beneficial results of basic crack propagation studies were reported in applications as diverse as surgical implants on one hand and nuclear reactor components on the other.

\section{Advanced Surface Processes for Optoelectronics-P MRS Symposium Proceedings,} Vol. 126

Organizers: T. Venkatesan (Bellcore), S. Bernasek (Princeton University), G. Stillman (University of Illinois), $H$. Temkin (AT\&T Bell Laboratories)

The symposium consisted of six separate sessions of oral presentations, one poster session and one oral session held jointly with Symposium A on Silicon Heteroepitaxy. Sixteen invited papers and 43 contributed papers were presented, with attendance at the sessions ranging from 50 to more than 130 attendees.

The symposium opened with an invited paper on gas phase sources for molecular beam epitaxy, by Mort Panish (AT\&T Bell Laboratories). Panish reviewed recent work on the use of gas source MBE, comparing this approach to III-IV structures grown by conventional MBE. Work by Robertson on mechanisms of $\mathrm{GaAs}$ growth from gas phase sources was also discussed.

In the joint session with Symposium A, John Bean (AT\&T Bell Laboratories) discussed technological prospects for $\mathrm{GeSi}$ epitaxy and reviewed the state of the art for GeSi photodetectors and light sources.

Several papers discussed recent research on the use of lasers for assisted optoelectronic processing. For example, J.E. Epler (Xerox PARC) discussed studies of laser-assisted MOCVD and laser annealing to incorporate silicon into III-V heterostructures. Glennis Orloff (Princeton University) described work on the laserassisted etching of $\mathrm{LiNbO}_{3}$ optical waveguide materials.

In the session on novel waveguide processing, Larry Coldren (University of California, Santa Barbara) discussed recent advances in reactive ion beam etching and related ion processing methods. Axel Sherer (Bellcore) followed this presentation with some recent examples of highly anisotropic structures made by reactive ion etching of InP and GaAs systems. 